\title{
Cellular Origin(s) of Congenital Diaphragmatic Hernia
}

\author{
Gabriëla G. Edel ${ }^{1,2}$, Gerben Schaaf ${ }^{3,4,5+}$, Rene M. H. Wijnen ${ }^{1 \dagger}$, Dick Tibboel ${ }^{1 \dagger}$, \\ Gabrielle Kardon ${ }^{6 t}$ and Robbert J. Rottier ${ }^{1,2 * t}$
}

${ }^{1}$ Department of Pediatric Surgery and Intensive Care, Erasmus MC-Sophia Children's Hospital, Rotterdam, Netherlands, ${ }^{2}$ Department of Cell Biology, Erasmus MC, Rotterdam, Netherlands, ${ }^{3}$ Department of Clinical Genetics, Erasmus MC, Rotterdam, Netherlands, ${ }^{4}$ Department of Pediatrics, Erasmus MC-Sophia Children's Hospital, Rotterdam, Netherlands, ${ }^{5}$ Center for Lysosomal and Metabolic Diseases, Erasmus MC, Rotterdam, Netherlands, ${ }^{6}$ Department of Human Genetics, University of Utah, Salt Lake City, UT, United States

OPEN ACCESS

Edited by:

David Warburton,

Children's Hospital Los Angeles,

United States

Reviewed by:

Juan A. Tovar

University Hospital La Paz, Spain

*Correspondence:

Robbert J. Rottier r.rottier@erasmusmc.n

TORCID:

Gerben Schaaf orcid.org/0000-0003-0189-9073

Rene M. H. Wijnen orcid.org/0000-0001-7266-9713

Dick Tibboel

orcid.org/0000-0003-4331-5398

Gabrielle Kardon

orcid.org/0000-0003-2144-4463

Robbert J. Rottier

orcid.org/0000-0002-9291-4971

Specialty section:

This article was submitted to Neonatology,

a section of the journal

Frontiers in Pediatrics

Received: 29 October 2021 Accepted: 03 November 2021 Published: 30 November 2021

Citation:

Edel GG, Schaaf G, Wijnen RMH, Tibboel D, Kardon $G$ and Rottier RJ (2021) Cellular Origin(s) of Congenital Diaphragmatic Hernia.

Front. Pediatr. 9:804496.

doi: 10.3389/fped.2021.804496
Congenital diaphragmatic hernia $(\mathrm{CDH})$ is a structural birth defect characterized by a diaphragmatic defect, lung hypoplasia and structural vascular defects. In spite of recent developments, the pathogenesis of $\mathrm{CDH}$ is still poorly understood. $\mathrm{CDH}$ is a complex congenital disorder with multifactorial etiology consisting of genetic, cellular and mechanical factors. This review explores the cellular origin of $\mathrm{CDH}$ pathogenesis in the diaphragm and lungs and describes recent developments in basic and translational $\mathrm{CDH}$ research.

Keywords: congenital diaphragmatic hernia $(\mathrm{CDH})$, diaphragm, pleuroperitoneal folds, perivascular cells, mesothelium

\section{INTRODUCTION}

In the past 25 years, the general mortality rate of $\mathrm{CDH}$ has decreased to approximately $25 \%$, but the mortality rate remained $50 \%$ in patients who receive extracorporeal membrane oxygenation (ECMO) $(1,2)$. In a recent study, $\mathrm{CDH}$ patients were categorized pre-ECMO in a low-risk, moderate-risk or high-risk cohort by their risk score (RS) for mortality, which is based on multiple risk factors, like location of the hernia and weight before ECMO (1). Change in individual likelihood of death overtime was different for each cohort: it was increased in the low risk group, decreased in the moderate risk group and unchanged in the high-risk group. Although the average survival of $\mathrm{CDH}$ patients increased in the past decades as a result of advancements in prenatal diagnosis, $\mathrm{CDH}$ pathogenesis remains still poorly understood. The main reason is that $\mathrm{CDH}$ is a complex congenital disorder with multifactorial etiology including genetic, cellular and environmental factors (3-5). In this review, we will discuss different tissues and cell types that are implicated in $\mathrm{CDH}$ pathogenesis and review recent developments in basic and translational research in $\mathrm{CDH}$.

\section{DIAPHRAGM/PPF}

The diaphragm is an essential muscle that is critical for proper respiration and forms a barrier between the thoracic and abdominal cavities (6). The diaphragm develops from multiple embryonic sources. Of primary importance are the pleuroperitoneal folds (PPFs). The PPFs are paired transient pyramidal-shaped structures located between the thoracic (pleural) and abdominal (peritoneal) cavities. The PPFs expand dorsally and ventrally across the cranial surface of the liver to give rise to the diaphragm's muscle connective tissue and central tendon (7-9). The somites, segmental structures lying adjacent to the neural tube, are the source of the diaphragm muscle. 
Muscle progenitors emigrate from the cervical somites to the nascent PPFs and as the PPFs expand, the progenitors migrate and fuse into the radial array of costal myofibers (7-11). In addition, the diaphragm is innervated by nerves that arise from the C3-C5 segments of the neural tube and it is vascularized by endothelial cells derived from the somites and likely splanchnic lateral plate mesoderm (8-10).

The PPFs are essential for the morphogenesis of the diaphragm and defects in the PPFs lead to CDH. Experiments in mice genetically tracking the development of the PPFs have established that the expansion of the PPFs drives the overall morphogenesis of the diaphragm and guide diaphragm muscle development (7). Defects in the development of the $\mathrm{PPF}$ are a significant source of $\mathrm{CDH}$. Most $\mathrm{CDH}$-implicated genes that have been examined are expressed in the PPF cells $(7,12-15)$. Mutations in CDH-implicated genes can lead to the incomplete expansion of the PPFs and thus lead to incompletely developed diaphragms that allow herniation of abdominal contents into thoracic cavity [e.g., (16)]. Alternatively, PPFs harboring mutations may be unable to signal to muscle progenitors [e.g., (7)], leading to defective progenitor migration to the PPFs, increased apoptosis, and/or decreased proliferation or differentiation into myofibers. In such scenarios, defects in the PPF cells lead to cell non-autonomous effects on neighboring muscle, resulting in weaker muscleless regions that allow herniation (7). To date, all evidence suggests that $\mathrm{CDH}$ arises from primary defects in the PPFs by either defective generation/migration of cell populations or impaired muscularization of the diaphragm, with little evidence to support a primary role for defects in muscle cells.

\section{LUNG MESOTHELIUM}

Pulmonary hypoplasia is another characteristic of $\mathrm{CDH}$. Although a lower amount of alveolar type I cells have been identified in nitrofen-induced $\mathrm{CDH}(17,18)$, the tissue that is primarily defective in $\mathrm{CDH}$-associated hypoplasia is not yet clear. A potential cellular source in $\mathrm{CDH}$ pathogenesis is the lung mesothelium, which contributes to different cell populations in the lung and is important for proper mesenchymal growth. The pleural mesothelium is a monolayer of cells that forms a lining around the lungs and is derived from the embryonic mesoderm (19). Although mesothelial cells are mesenchymal in origin, they have epithelial characteristics (20). During development, pulmonary mesothelial cells (PMCs) undergo epithelial-mesenchymal transition and differentiate to contribute to different cell populations in the pulmonary mesenchyme under the influence of active hedgehog signaling (21).

Several studies reported conflicting data to what extent the embryonic mesothelium contributes to the pulmonary mesenchyme. These studies employed different Wilm's tumor 1 (Wt1)-dependent driver lines, which is a gene encoding a zinc finger transcription factor expressed in mesothelial cells and diaphragm and that is associated with $\mathrm{CDH}$ (22). Wt1-dependent lines were used to trace $\mathrm{WT}^{+}{ }^{+}$mesothelial cells and analyzed the fate of the progeny at several time points, which most likely explains the variation in their results. Que et al. (23) reported that $\mathrm{WT}_{1}{ }^{+}$lung mesothelial cells contribute to vascular smooth muscle cells (SMCs) and to alveoli, which were potentially interstitial fibroblasts, alveolar myofibroblasts or endothelial cells. Dixit et al. chose a conditional strategy to lineage trace Wt1-expressing mesothelial cells and reported contribution of PMCs to vascular and bronchial smooth muscle cells, as well as fibroblasts (21). Cano et al. (24) focused on the contribution of PMCs to different lung cell types during embryonic lung development and observed contribution to a wider range of cell types including endothelial cells, airway and vascular smooth muscle cells, pulmonary cartilage and fibroblasts. Lastly, Von Gise et al. (25) found that labeling WT1 ${ }^{+}$cells at E10.5 resulted in a small contribution to bronchial- and vascular smooth muscle cells, while the majority differentiated into PDGFR $\alpha^{+}$. fibroblasts or PDGFR $\beta^{+} / \mathrm{NG}^{+}$-pericytes. Von Gise et al. (25) also showed that only fetal and not postnatal PMCs are capable of differentiating into pulmonary mesenchymal cell types. Postnatal PMCs remain in the mesothelial lining and do not migrate out or differentiate into other cell types. As such, postnatal PMCs do not seem to contribute to the lung parenchyma during normal lung homeostasis or after injury (25). In conclusion, mesothelial cells contribute to the bronchial- and vascular smooth muscle cell population as well as to fibroblasts and pericytes and that this only occurs during embryonic development and not postnatally $(21,25)$.

Besides being a progenitor source during lung development, the mesothelium also acts as a signaling source. One important pathway during development of the lungs is the FGF signaling pathway, in which FGF9 and FGF10 are essential (26). FGF10 is expressed in the lung mesenchyme, while FGF9 is expressed in the mesothelium and epithelium, signaling to the submesothelial- and subepithelial mesenchyme, respectively (27, 28). Mesothelial- and epithelial-produced FGFs have a different function: mesothelial-derived FGF9 is mainly responsible for mesenchymal growth by maintaining mesenchymal FGFWNT/ $\beta$-catenin signaling, whereas epithelial-derived FGF9 influences epithelial branching (29). One study reported reduced pulmonary FGF9 expression in the nitrofen-induced $\mathrm{CDH}$ rat model (30). However, recombinant co-cultures of fibroblasts and epithelial cells of nitrofen-treated- and control rats showed that not epithelial cells, but fibroblasts, are defective in nitrofeninduced hypoplastic lungs, showing decreased apoptosis and increased proliferation (31). Since the mesothelium is a source for mesenchymal fibroblasts $(21,23-25)$ and expresses FGF9 for the regulation of mesenchymal growth (29), the mesothelium is a potential source for $\mathrm{CDH}$-associated lung hypoplasia.

Cano et al. (24) showed that homozygous Wt1 knockout $\left(W t 1^{-/-}\right)$mice had a $\mathrm{CDH}$-like phenotype, abnormally fused lung lobes and reduced immunoreactivity for FGF9 in the pulmonary mesenchyme and mesothelium. A recent study reported similar findings and also reported an aberrant lung branching architecture already before closure of the diaphragm, when WT1 is expressed (32). When $W t 1^{-/-}$lungs were cultured ex vivo, lung branching was normal and any hypoplasia that had originated in vivo, was restored within $24 \mathrm{~h}$ ex vivo (32). Additional analyses showed that the space in the chest 
cavity - that is usually present for the lungs to grow-was nearly absent, explaining why culturing the lungs ex vivo without physical constraints recovered branching (32). Aberrant WT1 expression in the lung mesothelium results in defective lung development and $\mathrm{CDH}$ as result of limited space in the chest cavity and potentially by defective signaling and migration of mesothelial cells.

In summary, the mesothelium acts as a progenitor source and signaling center for the pulmonary mesenchyme to facilitate proper mesenchymal growth and cellular differentiation. These results associate the lung mesothelium as a cellular contributor to $\mathrm{CDH}$.

\section{(PERI)VASCULAR CELLS}

Besides a diaphragmatic defect and pulmonary hypoplasia, almost all CDH patients have pulmonary hypertension $(33,34)$, which is caused by an altered development of the pulmonary vasculature and pulmonary vascular remodeling (35). Changes in cell phenotypes, cellular proliferation and defective cell-cell communication have been proposed as underlying causes.

Previously, it was shown that $\mathrm{CDH}$ patients have higher abundance of contractile vascular SMCs, which were also more distributed along the proximo-distal axis of the lung vasculature (36). Although inhaled nitric oxide treatment is a successful treatment for preterm babies, it is only effective in a small number of $\mathrm{CDH}$ patients and even only beneficial in certain subsets of $\mathrm{CDH}$ patients (37). The pathological changes in vascular SMCs indicate a disturbed pulmonary vascular development and might explain the ineffectiveness of inhaled nitric oxide treatment in $\mathrm{CDH}$ patients. Another study by Acker et al. (38) showed increased proliferation of pulmonary arterial SMCs and pulmonary arterial SMC hyperplasia in a surgical CDH lamb model. This was not caused by an altered SMC phenotype, but by a disturbed interaction with pulmonary arterial endothelial cells (PAECs), indicating that defective endothelial signaling contributed to SMC hyperplasia and may therefore result in pulmonary hypertension (38). In the nitrofen-induced $\mathrm{CDH}$ mouse model, Kool et al. (39) observed an increased pericyte coverage in the large pulmonary vessels and pericytes had a more contractile phenotype. Furthermore, the basement membrane around the midsized vessels was discontinuous, indicating defective cross-talk between pericytes and endothelial cells (39). The impaired cross-talk between those two cell types and the altered pericyte phenotype may be the origin of pulmonary hypertension in $\mathrm{CDH}$.

$\mathrm{CDH}$ patients show a decreased vascular growth that contributes to poor disease outcomes. Acker et al. (40) showed in the surgical $\mathrm{CDH}$ lamb model reduced proliferation and tube formation capacity of PAECs. They also found a marked reduction in high-proliferative PAECs, which is a progenitor subpopulation of endothelial cells $(41,42)$. A reduced capillary network was also observed by Kool et al. (39) in the nitrofeninduced $\mathrm{CDH}$ mouse model. These results suggest that reduced proliferation of endothelial cells contributes to the decreased vascular growth in $\mathrm{CDH}$ patients.
Altogether, several cell types may disturb the lung vascular network, leading to $\mathrm{CDH}$-associated phenotypes. Abnormal phenotypes of endothelial cells, SMCs and pericytes and defective interactions between them may be the basis for the simplified vascular network and pulmonary hypertension in $\mathrm{CDH}$.

\section{CELLULAR MODELS IN CDH RESEARCH}

$\mathrm{CDH}$ cannot be attributed to one single source or defect, which makes it hard to study its pathogenesis, but new cell culture models can aid in improving insights at the cellular level. Recently, a cell culture model was described where PPFs from mice were isolated and cultured to outgrow and expand PPF fibroblasts, that maintained expression of key diaphragm genes (43). Pharmacological inhibition or genetic manipulation that causes $\mathrm{CDH}$ resulted in reduced in vitro proliferation in PPF-derived fibroblasts (43). Also, lung organoids were recently derived from induced pluripotent stem cells (iPSC) from fetuses and infants with $\mathrm{CDH}$ and showed reduced generation of lung progenitor cells and impaired epithelial- and mesenchymal differentiation (44). Recently, it was shown that organoid cultures can be obtained with a low input material from clinical samples, like tracheal aspirates from preterm newborns, and this method could also be used to grow organoids from $\mathrm{CDH}$ patients without the need of in vitro differentiation from iPSCs (45). Furthermore, endothelial cell culture models could aid in understanding defective endothelial cell function (40) and endothelial cell-SMC interaction (38). A differentiation protocol from human iPSCs to endothelial progenitor cells that mimics in vivo embryonic vascular development was recently published (42). This method can be used to generate iPSC-derived endothelial cells from $\mathrm{CDH}$ patients to eventually use these cells in cell co-culture systems, like organoid cultures. Although $\mathrm{CDH}$ is a multifactorial disease, in vivo experiments are limited and these kind of culture models will help to understand the pathology of $\mathrm{CDH}$ by specific cells, the interaction between different cell types and the molecular mechanisms in patient specific cultures.

\section{DISCUSSION}

In this review, we discussed cellular origins that are associated with $\mathrm{CDH}$ pathogenesis, including the diaphragm and PPF, lung mesothelium and (peri)vascular cells. All can contribute to a $\mathrm{CDH}$ phenotype, but also extrinsic factors play a role. Because pulmonary defects and alterations in the space of the chest cavity occurred prior to diaphragm closure and may even be the cause of a diaphragm defect (32), it is interesting to study the space in the chest cavity in other $\mathrm{CDH}$ models and potentially in human fetuses to serve as an early predictor for $\mathrm{CDH}$. To mimic limited chest space and compression, lung organoids have been subjected to mechanical pressure, which altered their development (44). These results show that extrinsic factors play a significant role in $\mathrm{CDH}$ pathogenesis and the influence of limited space and compression should be studied further, since Wt1 knock-out lungs still had the capacity to develop normally ex vivo, which is promising for potential treatment strategies (32). 
Intrapleural delivery of compounds has been suggested to target PMCs in idiopathic pulmonary fibrosis, since this may result in increased efficacy combined with reduced systemic toxicity of therapeutic agents $(19,46)$. This delivery strategy may also be interesting for targeting PMCs during lung development. Mesothelial mobilization is not only implicated in development of the lungs, but also in other organs, like the liver, heart and reproductive system (47). However, it has been shown that this process can differ between different organs and that mesothelial migration in developing lungs differs in timing and pathway dependency compared to other organs, like the heart (48). These features could be used for organ-specific targeting and makes the embryonic mesothelium an interesting therapeutic target.

In summary, defective development, communication or migration of cells from the diaphragm, the mesothelium and (peri)vascular cells of the lungs play an important role in $\mathrm{CDH}$ pathogenesis. Improved in vitro cell culture models and the

\section{REFERENCES}

1. Guner YS, Delaplain PT, Zhang L, Di Nardo M, Brogan TV, Chen Y, et al. Trends in mortality and risk characteristics of congenital diaphragmatic hernia treated with extracorporeal membrane oxygenation. ASAIO J. (2019) 65:509-15. doi: 10.1097/MAT.0000000000000834

2. Gupta VS, Harting MT, Lally PA, Miller CC, Hirschl RB, Davis CF, et al. Has Survival improved for congenital diaphragmatic hernia? A 25-year review of over 5000 patients from the CDH study group. Pediatrics. (2021) 147(3 MeetingAbstract):939. doi: 10.1542/peds.147.3_MeetingAbstract.939

3. Schulz F, Jenetzky E, Zwink N, Bendixen C, Kipfmueller F, Rafat $\mathrm{N}$, et al. Parental risk factors for congenital diaphragmatic hernia - a large German case-control study. BMC Pediatrics. (2021) 21:278. doi: 10.1186/s12887-021-02748-3

4. Mesas Burgos C, Ehrén H, Conner P, Frenckner B. Maternal risk factors and perinatal characteristics in congenital diaphragmatic hernia: a nationwide population-based study. Fetal Diagnosis and Therapy. (2019) 46:385-91. doi: 10.1159/000497619

5. Kardon G, Ackerman KG, McCulley DJ, Shen Y, Wynn J, Shang L, et al. Congenital diaphragmatic hernias: from genes to mechanisms to therapies. Dis Models Mech. (2017) 10:955-70. doi: 10.1242/dmm.028365

6. Merrell AJ, Kardon G. Development of the diaphragm - a skeletal muscle essential for mammalian respiration. Febs J. (2013) 280:4026-35. doi: $10.1111 /$ febs. 12274

7. Merrell AJ, Ellis BJ, Fox ZD, Lawson JA, Weiss JA, Kardon G. Muscle connective tissue controls development of the diaphragm and is a source of congenital diaphragmatic hernias. Nat Genet. (2015) 47:496-504. doi: 10.1038/ng.3250

8. Sefton EM, Gallardo M, Kardon G. Developmental origin and morphogenesis of the diaphragm, an essential mammalian muscle. Dev Biol. (2018) 440:6473. doi: $10.1101 / 278507$

9. Babiuk RP, Zhang W, Clugston R, Allan DW, Greer JJ. Embryological origins and development of the rat diaphragm. J Comp Neurol. (2003) 455:477-87. doi: 10.1002/cne.10503

10. Allan DW, Greer JJ. Embryogenesis of the phrenic nerve and diaphragm in the fetal rat. J Comp Neurol. (1997) 382:459-68. doi: 10.1002/(SICI)10969861(19970616)382:4\&lt;459::AID-CNE3\&gt;3.0.CO;2-1

11. Dietrich S, Abou-Rebyeh F, Brohmann H, Bladt F, Sonnenberg-Riethmacher E, Yamaai T, et al. The role of SF/HGF and c-Met in the development of skeletal muscle. Development. (1999) 126:1621-9. doi: 10.1242/dev.126. 8.1621

12. Ackerman KG, Herron BJ, Vargas SO, Huang H, Tevosian SG, Kochilas L, et al. Fog2 is required for normal diaphragm and lung development in mice and humans. PLoS Genet. (2005) 1:58-65. doi: 10.1371/journal.pgen.0010010 generation of patient-specific cultures will provide more insights in cellular and molecular mechanisms that underlie these defects and their use may be beneficial for identification and testing of putative therapeutic agents.

\section{AUTHOR CONTRIBUTIONS}

GE and GK wrote the manuscript. GS, RR, and DT carefully edited and revised the various versions of the manuscript and approved the final manuscript. RW revised and approved the final manuscript. All authors approved the final manuscript as submitted.

\section{FUNDING}

This work was supported by the Sophia Foundation for Scientific Research [Grant Nos. S17-20 (GE and RR)].

13. Carmona R, Cañete A, Cano E, Ariza L, Muñoz-Chápuli R. Conditional deletion of WT1 in the septum transversum mesenchyme causes congenital diaphragmatic hernia in mice. eLife. (2016) 19:e16009. doi: 10.7554/eLife.16009.013

14. Clugston RD, Zhang W, Greer JJ. Gene expression in the developing diaphragm: significance for congenital diaphragmatic hernia. Am J Physiol Lung Cell Mol Physiol. (2008) 294:L665-75. doi: 10.1152/ajplung.00027.2008

15. Paris ND, Coles GL, Ackerman KG. Wt1 and beta-catenin cooperatively regulate diaphragm development in the mouse. Dev Biol. (2015) 407:40-56. doi: 10.1016/j.ydbio.2015.08.009

16. Clugston RD, Zhang W, Alvarez S, de Lera AR, Greer JJ. Understanding abnormal retinoid signaling as a causative mechanism in congenital diaphragmatic hernia. Am J Respir Cell Mol Biol. (2010) 42:276-85. doi: 10.1165/rcmb.2009-0076OC

17. Takayasu H, Nakazawa N, Montedonico S, Sugimoto K, Sato H, Puri P. Impaired alveolar epithelial cell differentiation in the hypoplastic lung in nitrofen-induced congenital diaphragmatic hernia. Pediatr Surg Int. (2007) 23:405-10. doi: 10.1007/s00383-006-1853-y

18. Nguyen TM, Jimenez J, Rendin LE, Müller C, Westergren-Thorsson G, Deprest J, et al. The proportion of alveolar type 1 cells decreases in murine hypoplastic congenital diaphragmatic hernia lungs. PLoS ONE. (2019) 14:e0214793. doi: 10.1371/journal.pone.0214793

19. Batra H, Antony VB. The pleura mesothelium in development and disease. Front Physiol. (2014) 5:284. doi: 10.3389/fphys.2014.00284

20. Mutsaers SE. Mesothelial cells: their structure, function and role in serosal repair. Respirology. (2002) 7:171-91. doi: 10.1046/j.1440-1843.2002.00404.x

21. Dixit R, Ai X, Fine A. Derivation of lung mesenchymal lineages from the fetal mesothelium requires hedgehog signaling for mesothelial cell entry. Development. (2013) 140:4398-406. doi: 10.1242/dev.098079

22. Wilm B, Muñoz-Chapuli R. The role of WT1 in embryonic development and normal organ homeostasis. In: Hastie N, editor. The Wilms' Tumor (WT1) Gene: Methods and Protocols. New York, NY: Springer New York (2016). p. 23-39.

23. Que J, Wilm B, Hasegawa H, Wang F, Bader D, Hogan BLM. Mesothelium contributes to vascular smooth muscle and mesenchyme during lung development. Proc Natl Acad Sci USA. (2008) 105:16626. doi: 10.1073/pnas.0808649105

24. Cano E, Carmona R, Muñoz-Chápuli R. Wt1-expressing progenitors contribute to multiple tissues in the developing lung. Am J Physiol Lung Cell Mol Physiol. (2013) 305:L322-32. doi: 10.1152/ajplung.00424.2012

25. von Gise A, Stevens SM, Honor LB, Oh JH, Gao C, Zhou B, et al. Contribution of Fetal, but not adult, pulmonary mesothelium to mesenchymal lineages in lung homeostasis and fibrosis. Am J Respir Cell Mol Biol. (2016) 54:222-30. doi: $10.1165 / \mathrm{rcmb} .2014-04610 \mathrm{O}$ 
26. Danopoulos S, Shiosaki J, Al Alam D. FGF signaling in lung development and disease: human versus mouse. Front Genet. (2019) 10:170. doi: 10.3389/fgene.2019.00170

27. White AC, Xu J, Yin Y, Smith C, Schmid G, Ornitz DM. FGF9 and SHH signaling coordinate lung growth and development through regulation of distinct mesenchymal domains. Development. (2006) 133:150717. doi: 10.1242/dev.02313

28. Yin Y, Ornitz DM. FGF9 and FGF10 activate distinct signaling pathways to direct lung epithelial specification and branching. Sci Signal. (2020) 13(621). doi: 10.1126/scisignal.aay4353

29. Yin Y, Wang F, Ornitz DM. Mesothelial- and epithelial-derived FGF9 have distinct functions in the regulation of lung development. Development. (2011) 138:3169-77. doi: 10.1242/dev.065110

30. Takahashi H, Friedmacher F, Fujiwara N, Hofmann A, Puri P. Pulmonary FGF9 gene expression is downregulated during the pseudoglandular stage in nitrofen-induced hypoplastic lungs. Eur J Pediatr Surg. (2014) 24:75-8. doi: 10.1055/s-0033-1351392

31. van Loenhout RB, Tseu I, Fox EK, Huang Z, Tibboel D, Post M, et al. The pulmonary mesenchymal tissue layer is defective in an in vitro recombinant model of nitrofen-induced lung hypoplasia. Am J Pathol. (2012) 180:48-60. doi: 10.1016/j.ajpath.2011.09.032

32. Gilbert RM, Schappell LE, Gleghorn JP. Defective mesothelium and limited physical space are drivers of dysregulated lung development in a genetic model of congenital diaphragmatic hernia. Development. (2021) 148:dev199460. doi: 10.1242/dev.199460

33. Kool H, Mous D, Tibboel D, de Klein A, Rottier RJ. Pulmonary vascular development goes awry in congenital lung abnormalities. Birth Defects Res C Embryo Today Rev. (2014) 102:343-58. doi: 10.1002/bdrc.21085

34. Varghese NP, Tillman RH, Keller RL. Pulmonary hypertension is an important co-morbidity in developmental lung diseases of infancy: bronchopulmonary dysplasia and congenital diaphragmatic hernia. Pediatr Pulmonol. (2021) 56:670-7. doi: 10.1002/ppul.25258

35. Mous DS, Kool HM, Wijnen R, Tibboel D, Rottier RJ. Pulmonary vascular development in congenital diaphragmatic hernia. Eur Respir Rev. (2018) 27:170104. doi: 10.1183/16000617.0104-2017

36. Sluiter I, van der Horst I, van der Voorn P, Boerema-de Munck A, Buscop-van Kempen M, de Krijger R, et al. Premature differentiation of vascular smooth muscle cells in human congenital diaphragmatic hernia. Exp Mol Pathol. (2013) 94:195-202. doi: 10.1016/j.yexmp.2012. 09.010

37. Yang MJ, Russell KW, Yoder BA, Fenton SJ. Congenital diaphragmatic hernia: a narrative review of controversies in neonatal management. Transl Pediatr. (2021) 10:1432-47. doi: 10.21037/tp-20-142

38. Acker SN, Seedorf GJ, Abman SH, Nozik-Grayck E, Kuhn K, Partrick DA, et al. Altered pulmonary artery endothelial-smooth muscle cell interactions in experimental congenital diaphragmatic hernia. Pediatr Res. (2015) 77:511-9. doi: $10.1038 /$ pr.2015.13

39. Kool HM, Bürgisser PE, Edel GG, de Kleer I, Boerema-de Munck $A$, de Laat I, et al. Inhibition of retinoic acid signaling induces aberrant pericyte coverage and differentiation resulting in vascular defects in congenital diaphragmatic hernia. Am J Physiol Lung Cell Mol Physiol. (2019) 317:L317-L31. doi: 10.1152/ajplung.001 04.2018
40. Acker SN, Seedorf GJ, Abman SH, Nozik-Grayck E, Partrick DA, Gien J. Pulmonary artery endothelial cell dysfunction and decreased populations of highly proliferative endothelial cells in experimental congenital diaphragmatic hernia. Am J Physiol Lung Cell Mol Physiol. (2013) 305:L943-L52. doi: 10.1152/ajplung.00226.2013

41. Wakabayashi T, Naito H, Suehiro JI, Lin Y, Kawaji H, Iba T, et al. CD157 marks tissue-resident endothelial stem cells with homeostatic and regenerative properties. Cell Stem Cell. (2018) 22:384-97 e6. doi: 10.1016/j.stem.2018.01.010

42. Farkas S, Simara P, Rehakova D, Veverkova L, Koutna I. Endothelial progenitor cells produced from human pluripotent stem cells by a synergistic combination of cytokines, small compounds, and serum-free medium. Front Cell Dev Biol. (2020) 8:309. doi: 10.3389/fcell.2020.00309

43. Bogenschutz EL, Sefton EM, Kardon G. Cell culture system to assay candidate genes and molecular pathways implicated in congenital diaphragmatic hernias. Dev Biol. (2020) 467:30-8. doi: 10.1016/j.ydbio.2020.07.013

44. Kunisaki SM, Jiang G, Biancotti JC, Ho KKY, Dye BR, Liu AP, et al. Human induced pluripotent stem cell-derived lung organoids in an ex vivo model of the congenital diaphragmatic hernia fetal lung. STEM Cells Transl Med. (2021) 10:98-114. doi: 10.1002/sctm.20-0199

45. Eenjes E, van Riet S, Kroon AA, Slats AM, Khedoe PPSJ, Boerema-de Munck A, et al. Disease modelling following organoid-based expansion of airway epithelial cells. Am J Physiol Lung Cell Mol Physiol. (2021) 321:L775-86. doi: 10.1152/ajplung.00234.2020

46. Hocking A, Tommasi S, Sordillo P, Klebe S. The safety and exploration of the pharmacokinetics of intrapleural liposomal curcumin. Int J Nanomedicine. (2020) 15:943-52. doi: 10.2147/IJN.S237536

47. Koopmans T, Rinkevich Y. Mesothelial to mesenchyme transition as a major developmental and pathological player in trunk organs and their cavities. Commun Biol. (2018) 1:170. doi: 10.1038/s42003-018-0180-x

48. Timo HL, Carsten R, Jennifer K, Regine H, Franziska G, Irina W, et al. Mesothelial mobilization in the developing lung and heart differs in timing, quantity, and pathway dependency. Am J Physiol Lung Cell Mol Physiol. (2019) 316:L767-83. doi: 10.1152/ajplung.00212.2018

Conflict of Interest: The authors declare that the research was conducted in the absence of any commercial or financial relationships that could be construed as a potential conflict of interest.

Publisher's Note: All claims expressed in this article are solely those of the authors and do not necessarily represent those of their affiliated organizations, or those of the publisher, the editors and the reviewers. Any product that may be evaluated in this article, or claim that may be made by its manufacturer, is not guaranteed or endorsed by the publisher.

Copyright (C) 2021 Edel, Schaaf, Wijnen, Tibboel, Kardon and Rottier. This is an open-access article distributed under the terms of the Creative Commons Attribution License (CC BY). The use, distribution or reproduction in other forums is permitted, provided the original author(s) and the copyright owner(s) are credited and that the original publication in this journal is cited, in accordance with accepted academic practice. No use, distribution or reproduction is permitted which does not comply with these terms. 